\title{
On Nepalese English Discourse Granting Citizenship to English in Nepal via Corpus Building
}

\author{
Sajan Kumar Karn
}

\begin{abstract}
The adoption and adaptation of the English language across the globe have given birth to several nativized varieties such as Indian English, Japanese English, Singaporean English etc. A good number of papers have appeared to argue that a divergent variety of English has grown in Nepal with its own distinctive features at all language levels. The emergence and growth of new English in Nepal, however, have generated heated debates amongst scholars. Whereas some argue that English should be owned and promoted for it has become an inevitable component of not only Nepalese academia but also socio-political life, others fear the development as fatal to indigenous linguistic and cultural heritages. In this article, I propose to own Nepalese English but cautiously i.e. the way it does not ruin our local inheritances. Nonetheless, I primarily advocate building a corpus of Nepalese English to authenticate it and pave the way for owning
\end{abstract}

Key words: Nepalese English, Corpus, Linguistic Imperialism, Nativization, Identity

\section{Backdrop}

I teach a course on English phonology and yet another on applied linguistics. During the course of instruction, I often encounter a question (maybe many of my colleagues and seniors also come across such a question): 'which English do you (or 'we') use, Sir?' Perhaps, the impetus behind such a question to me is the fact that I teach a course on English phonology but my accent is neither identical to the American English nor towards Received Pronunciation. Of course, I know the answer of the question due to my association with applied linguistics, particularly my interest and study in world Englishes ; however, I often keep taciturn. It is because I fear that my answer will instigate further questions and debates which I might be unable to counter satisfactorily. My answer and perhaps your answer would be the same: 'Nepalese English, we use'. Occasionally, I do answer and confront a set of additional questions: What makes you claim that such a thing exists at all? Where is the dictionary for it? Where is its grammar? What are the lexis, structural patterns, phonological and pragmatic features that set Nepalese English apart from other native and non-native varieties? How shall we determine whether a particular sentence is acceptable in Nepalese English? Has the policy making body recognized it duly? Do the English language teachers and students approve such a variety? and so forth. While writing this paper, such thoughts revolved around my mind and led me to the following direction I have taken in this essay.

\section{Can we do without English?}

Nobody can deny that English has become the flesh and blood of Nepalese academia today. Owing to the continued massive use of English and growing craze for it in recent years, we can hardly think of condensing its role in Nepalese education in foreseeable future. Despite the 
criticisms indicating its undesirable effects on local languages and cultures (Giri, 2009), the use of English is proliferating by leaps and bounds. Beside the mushrooming of private schools, recently a pair of conspicuous changes in community schools have been that English starts from Grade I and many of them also have begun separate English medium sections in each grade to shake hands with private schools where English in not only a medium of instruction but also that of communication on their premises. We are already aware that English is the selling point in virtually all private educational institutions. Many parents send their children to private schools and when their children are able to say "Good Morning Papa”, "Tata Mommy”, "See you again, Uncle”, they become astonishingly happy. This seems to give them utter delight and also a sense of educational achievement in their pupils, which is sheer ignorance though. Similarly, Nepalese colleges-public or private teach all the courses except Nepali in English medium. In the university examinations, test papers contain questions in only English which entails both teachers and students to opt for English in the classrooms as well. Some English is heard in most educational gatherings such as conferences, seminars, meetings, trainings, release ceremonies, debates, contests, etc. Of late, textbook writing in the English medium has increased. To cater to the needs of the college students, textbooks of all streams-Education, Science, Management, Humanities are being published in English. In response to literary colonialism, textbooks on English Language Teaching (ELT) and other disciplines have begun to be published in English medium locally. Some of the recent local publications on ELT are New Generation English, Expanding Horizons in English, New Paradigm, Reading Beyond the Borders etc. Creative writing in English has stepped up which has resulted into the creation of Nepal made English literature. 'A Suicide Note' (Gopi Sapkota), 'Star and Fireflies' (Prakash Subedi), 'Asian Poems for Young Readers' (Orient Longman) etc. are some of the anthologies by Nepalese poets. Similarly, 'Echoes of the Himalayas' (D. B. Gurung), 'Tilled Earth' (Majushree Thapa), 'Fifteen and Three Quarters' (Richa Bhattarai) etc. are some stories in English penned by Nepalese storywriters.
'The Guru of Love' by Samrat Upadhyay, 'The Tutor of History' (Manjushree Thapa), 'Come Tomorrow' (Mani Dikshit) etc. are some of the novels by Nepalese authors. Similarly, translation of Nepalese literature into English is also in rise recently. Stories of Conflict and War (Govinda Raj Bhattarai), Selected Nepali Poems (Taranath Sharma), Socrates' Footsteps (Novel) (Balram Adhikari) etc. are some translated literary works from Nepali into English. Both originally created and translated works show characteristics of Nenglish (Nepalese English) (Rai, 2007). All these activities attest the escalation of English in Nepalese academia.

Many of the Nepalese and non-Nepalese scholars have duly understood this reality and have accepted the inevitable role of English in Nepalese education (Malla, 1977; Jha, 1989; Eagle, 1999; Sharma, 2006; Bhattarai \& Gautam, 2005; Kansakar, 2011). Acknowledging the need for English, Kansakar (1998) maintains that English occupies an important place in the development of the country and this is why ELT has become an indispensable element of Nepalese education. Bhattarai and Gautam (2007) go even a step further and argue that the knowledge of English is inevitable to maintain quality education and also to be considered elite. Though it is not justifiable to equate quality education with knowledge of English, the role of English in Nepalese education seems immensely crucial. English that is said formally to have been in vogue as a foreign language in the schools and colleges of Nepal for more than one and half a centuries seems to have in reality surreptitiously assumed the role of second language recently ( Bhattarai \& Gautam, 2005; Sharma, 2006).

In the section below, I write about how English has crossed the boundary of educational territories and has become a part and parcel of the Nepalese social life.

\section{English penetrates Nepalese social life}

In educational institutions, English is not only taught and learnt as a subject and used as a medium of instruction within the classroom periphery but it is also used as a means of communication which has widened its status and has taken it to day-to-day Nepalese life. Perhaps, 
it will not be unjustified to say that most Nepalese use at least some English. The only difference is whereas educated people use more English, noneducated ones use relatively less English. Eagle (1999) observes:

"English is the second most widespread language in Nepal in terms of popularity, education, and use. It is spoken at all socio-economic levels, by both literate and non-literate people. No statistics are available for the number of people who speak or read English. The general impression is that a large percentage of the population speaks at least some English, with varying levels of accuracy and fluency" (p. 302).

There might be a question of amount of English but English is there in people's life either through code-switching or code-mixing or without such mixing and switching. Karn (2009) argues that English in Nepal as elsewhere has two faces viz. Englishization of the languages in Nepal and nativization of English. In other words, English is present in the local languages through codemixing or code-switching on the one hand and it is gaining more Nepaleseness through considerable adjustments in forms and meanings due to the influence of local languages such as Nepali, Maithili, Newari etc on the other (See Appendix I).

Following Jha (1989), English is used in socio-cultural gatherings, family weddings, birthday celebrations and also interpersonal communications. Further he adds that without knowledge and skills of the English language, it is almost impossible to get a job. Almost ninety percent of jobs in Nepal require command over English (Cited in Eagle, 1999, p. 304). Even the advertisements for peons, watchmen etc. demand some knowledge of English. In many cases though the cause is 'English elevates prestige', it is growing as a more spontaneous means of communication lately.

Although the formal documents such as Secondary Curriculum Introductory Training Booklet published by Ministry of Education designate English as 'a foreign language', the actual scenario is utterly different as I stated in previous section. No other foreign languages such as French or Chinese are used as extensively as English is used in Nepal which was asserted by Second National
Convention of Tribhuvan University Teachers of English:

English cannot be considered as a foreign language like French or Arabic. In the context of Nepal, it is the only language of education and communication for majority of people and the number of such people is increasing at fast rate. It needs therefore to be given the recognition of this reality in national language policy documents and funds should be accordingly allocated to teaching/ learning of English in Nepal (Cited in Yadav, 1990, quoted in Eagle, p.280).

It is truly very unfortunate that the constitution of Nepal does not make even the mention of English that is so much engrossed in people's life. Highlighting the significance of English in Nepal, Malla(1977) wrote long back "English is undoubtedly of vital importance for accelerating the modernization process in Nepal, and in so far as education is an agent of such a process the place of English in Nepalese education as a foreign language is secure and unassailable" (p. 12). He assured the status of English as an expanding circle English; however it has arguably travelled beyond and taken the position of outer circle English today. Backing Malla, Sharma (2006) contends "A developing country like Nepal cannot ignore the vast space open to the process of progress and modernization through the knowledge of English" (p. 25). Additionally, thousands of Nepalese go abroad everyday in the pursuit of job or education and contribute in the educational and economic development of the country and it has been feasible only through the knowledge of English. Therefore, English for Nepalese has become a tool to achieve education and prosperity both. Kansakar (2011) duly maintains "the need for English in Nepal is quite obvious and this is likely to increase in the fields of international communication, diplomacy, business relations, and educational development" (p.123). Further, the need for English is bound to breed in Nepal because of growing unemployment and lack of any concrete plan for poverty alleviation. It is worth mentioning what Subhas Nembang, Chairman of the present Constituent Assembly said in the Inaugural speech of Fifteenth International NELTA Conference in 2010:

The importance of the English language has become universal. Undoubtedly, it has been widely 
used in the present day. Without the knowledge of the English language, our access to half of the world would become inaccessible. Our ability to communicate with the large part of the world and do business with them would be extremely limited. We will miss all the nice opportunities that more than half of the world offers to us for our all round development. (Report of Fifteenth International NELTA Conference, 2010, p. 8)

My own observation is that we need English. In fact, we need more English; our forthcoming generations need even more English to prosper at national and international spheres, however not at the expense of local languages and cultures. We have every right to use prickly words to criticize English such as hegemony, linguistic colonization, linguistic and cultural imperialism, dominance and so forth and they might be (are) indisputable to a greater extent but we cannot close our eyes to the reality that English has become a fundamental skill to know the world and let the world know us. We are aware of the fact that despite the strong protests made by Gandhi in India "against the alienation induced by English" (Philipson, 2007, p. 35 ), it grew up and today it has the status of second language. I foresee the similar circumstance here in Nepal. Phyak (2009) hints at the cultural domination of English in Nepal. He affirms that the spread of English gives rise to many socio-political issues which have not been given due space in the studies so far. Critiquing against taking-asgranted-dominant-role of English from language policy perspective, he (2009) contends that we have to critically look at the space of English in our whole language-in-education policy. He joins Pennycook (1994) with his cultural politics of English and Cangarajah (1999) while looking at ELT from policy perspective with focus on local realities. His worry is justified. Nevertheless, I am of the opinion that it is time we perceived English from different angle and found out the way English does not harm our socio-cultural heritage rather leads us to the road of headways. It is significant to quote what Lav Deo Awasthi, joint-secretary, Ministry of Education, Nepal said "We have to look how English cannot be seen as problem for our students. It can be a tool to enhance the quality of their life" (Report of Fifteenth International NELTA Conference, 2010, p. 8). Graddol (2006) upholds that the spread of global English is not the straight cause of language endangerment unlike the allegations. This in fact is a very remarkable at the time people have feared the possible threats of English to Nepalese language and cultures. Yadav (2009) is in favor of shrinking the role of English in Nepalese education. He proposed that English should begin from Grade VIII in order to promote mother tongue based multilingual education. This seems very difficult to digest for many parents who have an illusion that English is education and it is English that knocks the door of opportunities. The Interim Constitution of Nepal (2007) has vowed to implement multilingual education and has provided for the educational and cultural rights of the speakers of minority languages. The mother tongue based multilingual education program started at primary level in January 2007 to protect the linguistic right of every child to learn his/ her mother tongue to succeed academically. Nevertheless, the preliminary reactions and results are not that satisfactory. Nepalese parents who have developed a kind of obsession for English are not ready to opt for Nepalese languages based education system.

Having concluded that the growth of English is unstoppable in predictable future, it is very essential that we lay our efforts towards how it can be owned with care. Nepalese educationists, applied linguists and ELT scholars should contemplate on how we can live with English i.e. how we can befriend English, rather than on critiquing against English and thinking about how English can be driven away.

In the sections that follow, I endeavor to reveal how English is becoming our own language and what ways we can develop affirmative attitude towards it.

\section{From English to Nepalese English}

As far as I know it was Rai (2006) who for the first time formally presented a paper in a NELTA Conference on 'English, Hinglish and Nenglish' which was later developed into an article in Journal of NELTA. He admits that there are lacks of materials to support the claim but it is true that "a different kind spoken as well as written English is emerging in Nepal ..." (p.39) (See Appendix II). This was a milestone for the acceleration of 
debates about new English in Nepal. Since then, a good number of discourses have attempted to justify that different English exists in Nepal. However, Brett (1999) was the first person to propose that different English existed in Nepal. She justified her claim by compiling a miniature databank of peculiar English expressions used in Nepalese schools (see Appendix I). Drawing on Rai (2006) and Brett (1999), Karn (2006) stated "English has been acclimatized according to Nepali soil, Nepali culture and Nepali accent and so on. To say more explicitly, some kind of Nepaliness has been added to the English used here. (p.75).

Thus, the use of Nepalese English is not limited to spoken domain; English literature created in Nepal and students' writings vividly exhibit the idiosyncrasies. Supporting the development, Daniloff- Merrill (2010) advocates for the recognition of Nenglish as Nepalese learners express their identity through it. With the analysis of essays by Nepalese students, she shows that Nenglish is an established variety of English through its use in essays.

Awasthi et. al. (2010), acknowledging the emergence of new English in Nepal, states in New Generation English, one of the textbooks of newly revised curricula for Three Year B. Ed:

We are aware of the fact that in the present day worlds, there is no longer one English, there are many Englishes. So there are texts not only from the native English varieties but also from different regions where non-native English variety is flourishing. ...........We have also introduced a considerable portion of Nepali English (Nenglish) as well which includes three short stories (one translated), one poem and one essay (Page Not Given).

This is truly a giant step in the recognition of a distinct variety of English in Nepal. Phyak \& Karn (2010) presented a paper in Asian English Spoken Language Corpus workshop in Kathmandu and raised the issue strongly that it was very essential to build corpus for Nepalese English in order to authenticate it. They added ample data to the previously collected samples by Rai (2010) and Brett (1999). They also raised an issue over the name of New English in Nepal which has been discussed in the following section:

\section{What's in name?}

What's in name? That which we call a rose. By any other name would smell as sweet.

Shakespeare

For Shakespeare, name did not mean much. In a party, he made Romeo address Juliet by the name of Rosalind but did not mean Rosalind rather Juliet herself. Likewise, whether we know English spoken in Nepal by the name of Nenglish, Nepali English, Nepalese English, the thing perhaps should be the same. However, many a time, label counts a lot and it seems to apply in the case of English in Nepal as well.

Whereas Kachru(1996), Brett (1999) and Hartford(2006) use Nepali English, Rai (2006) prefers Nenglish which is backed by DaniloffMerril (2010). Verma(1996) uses Nepali Variety of English (2006) but Crystal (1999) makes use of Nepalese English. It is Nepalese English that convinces Phyak and Karn (2010) for a couple of reasons. The phrase, Nenglish has been interpreted as slang by some respondents of Daniloff-Merril (2010) and also suggests the influence of only the Nepali language on English excluding Maithili, Newari, Bhojpuri, Limbu etc. The same is the case with Nepali English. On the contrary, the phrase 'Nepalese English' is more inclusive and a reasonable name for English used in Nepal.

\section{Scepticism}

Going against the worldwide wave of nativization of English, Duwadi (2010) raises scepticism, however. He doubts if Nepalese English (Nenglish) is an inevitable reality or barely a mirage. He perceives the nativization of English in Nepal and its adoption in teaching to be anarchy. This is utterly unpersuasive, though. He terms the campaign of Nepalese English to be impracticable which I perceive to be sensible and visionary. To ignore local realities is to ignore our own identity. We invent identity through Nepalese English while we use it. Owning English that incorporates local values and cultures is the only way to secure the position of English in Nepal at the time English has become the victim of prickly arrows from various sides. He seems to be advocating the use of Standard English which is itself on its deathbed because of the emergence of Estuary English. Low and Graham (2000) argue that "there is some 
speculation about whether Estuary English will eventually replace $\mathrm{RP}$ as Britain's most influential accent" (p.158). I would like to quote Cook (1999, p. 187) to answer Duwadi (2010)'s qualm "Standard English is a native speaker model which may be unattainable for many second language learners. Therefore, it may be unrealistic to use a native speaker model for language learners who, by definition can "never become native speakers without being reborn" (Cited in Farrel \& Martin S., 2009, p. 3). Like Duwadi (2010), there are many who argue that it is important to teach native speaker's variety i.e. Standard English. However, they seem to ignore a crucial reality that preference of Standard English can devalue other varieties of English (Nepalese English) that exist around the world which is a kind of racism from social justice point of view. Many speakers of World Englishes use English in their own way as an expression of their identity and their cultural values. Farrel \& Martin (2009) recommend that it is wise to value learners' English and prepare learners for intercultural communication. In the case of Nepal, valuing learners' English obviously means acknowledging the use of Nepalese English. Sharma (2008) also argues that "local varieties of Englishes in both Outer and Expanding Circles must be acknowledged and given space in curricula and classroom teaching....." (p. 129). Today, the distinction between three concentric circles of Kachru seems to have ruptured and therefore we should recognize world English which according to Rajgopalan (2004, p.113) "belongs to everyone who speaks it but it is nobody's mother tongue" " (Cited in Harmer, 2007, p.18). Nobody solely owns English anymore, in other words-or perhaps we could say that we all native and non-native speakers alike, own it together in a kind of international shareholders' democracy since whatever English we speak-Indian English, British English or Malaysian English-we have or should have equal rights as English users"( ibid., p.18).

In the following section, I discuss whys and hows of owning English in Nepal:

\section{Inventing identity in English}

The journey of English to Nepalese English itself is an indication that the tide of nativization is not going to recede unless its direction reverses which is not likely. Language users seek identity in the language they use. Perhaps, Nepalese people use and prefer to use Nepalese English for it betrays Nepaleseness. There have been many scholars who have concluded that the users of English across the globe are reinventing their identity through English. Ferguson (2006), for example, goes for the ownership of English through appropriation. He overviews that local variety of English becomes an instrument of identify for the users : “...... many users wish to project a distinctive identity in and through their local variety, it follows, so some argue, that that to deny the recognition to local varieties of English is to withhold acceptance of identities that those varieties express. To appropriate English is to develop a sense of ownership, to claim the language as one's own... .."(p. 166). In the same way, Graddol (2006) is of the opinion that "....Asian countries are in the process of reinventing national identity at the same time as they are legitimating the hegemony of English by making it a central feature of national development. In most cases, this paradox is resolved by appropriating English in ways which do least damage to their national language and identity" (p.117). At the time while new constitution is being drafted in Nepal, Karn (2008) raises a doubt if other Nepalese languages be can be more neutral than English since all languages of Nepal are community specific:

"The role of the English language in the New Nepal can hardly exaggerated as this can stand as the icon of unity and national harmony since all other languages have been alleged to belong to specific communities. English can be an instrument to strengthen loktantra and promote human rights. As the nation is undergoing a transitional stage, everything is in the state of flux. This is the high time the nation pondered over the language policy in general and ELT strategy in particular" (Karn, 2008, p. 4).

Sharma (2009), in the following paragraph, expresses similar view. The Nepali language which has been and is likely to assume the role of official language in new constitution tomorrow is the byproduct of the imposition of 'one state one language' policy and it is high time the biased policy was subverted alleviating English to the linking role. 
"An external language as a lingual franca for the many linguistic communities would in some ways create a new platform where the linguistically less privileged communities would have an alternative that does not privilege any particular community. In some ways, people who do not speak the politically dominant Nepali (Khas) language as their primary language-which has been erstwhile imposed upon them by society, politics, and education as our language-would not be a disadvantage with this new medium, which many would deem politically neutral. Indeed English would not only help subvert the implicitly, one nation, one language policy of Nepal; from another important perspective, the use of English as the link / official languages would also help the new nation in competing in the global intellectual market" (Sharma, 2009, p. 15).

Many people are afraid of the role of English as exploiter but in recent days the role of English has been transformed. According to Brutt-Griffler (2002), Africans and Asians received English as a means of exploitation but have transformed it into a means of resistance. English has empowered them to resist colonization (Cited in Ferguson, 2006, p.117). This is true to a greater extent. Larsen-Freeman 's (2007) suggestion is worth in that she encourages us to move from ideology to empowerment and the best way to do so is to teach English in a way that empowers, does not impose. Kumaravadevelu(2001) who advocates pedagogy of particularity argues that to ignore local exigencies is to ignore lived experiences. To extend this, I infer that instead of adhering to alien Standard English like British or American English, it is wise to acknowledge locally growing Nepalese English.

Since English is in the process of becoming our own language, it is futile to protest against the alienation or denationalization induced by English. There are many advantages of owning Nepalese English. Nepalese English can express cultural attitudes of Nepalese. The recognition of Nepalese English can develop local scholarship in English. Once Nepalese English is codified, localisation of ELT material production can further be boosted. Translation of Nepalese texts into English is in rise and authentication of Nepalese English can add native flavour in it. However, the challenge before us in owning English is the lack of corpus.

In the following section which is the crux of this paper, I try to justify why corpus is necessary for newly developed Nepalese English.

\section{Whys of Nepalese English corpus}

A corpus refers to databank of a language which has actually occurred-whether written or spoken or a mixture of the two (Cook, 2003, p.73). Corpus, according to Reppen and Simpson (2002), explores actual patterns of language use and can also be used as a tool for developing materials for classroom language instruction. Some people have argued that corpus findings should fundamentally alter language teaching. It also provides tremendous insights as to how language use varies in different situations, such as spoken versus written or formal interactions versus casual conversation (p.92). Though its applications are many, of late, scholars have recognized the importance of corpus in language teaching recently.

Sah (2011) has concluded in her study that Nepalese teachers and students have positive attitude towards newly growing English in Nepal. Her informants also agreed that corpus needs to be developed for the newly growing English in Nepal.

I forward the following rationales behind constructing a corpus for Nepalese English:

- Much has been talked about Nepalese English. However, little serious attempt has been made to show what lexis, structural patterns, phonological and pragmatic features occur more frequently in Nepalese English that differentiates it from other varieties of English such as British English, American English, Indian English etc. Reppen and Simpson (2002) argue that it is corpus that helps to explore similarities and differences across regional varieties of English.

- Many literary works by Nepalese writers such as poems, novels, essays, stories exhibit the typical features of Nepalese English. Unfortunately, in the paucity of corpus, authenticity of such creative works is often suspected.

- Standardization of Nepalese English has not moved ahead in the absence of corpus. Once 
corpus for Nepalese English is constructed, it will guide the act of codification, dictionary making and grammar writing which consequently will help in its authentication.

- Teachers and students often come across a question-which English do we use (teach)? At times, I have encountered such a question but in the absence of documents that can validate my claim, I keep mum. In the absence of corpus, it has been truly difficult to claim what actually represents Nepalese English.

- In addition to the major national varieties of English, several other nativised varieties such as Indian English has got its own corpus which has paved the way for its authentication and recognition nationally and internationally.

- English teaching textbooks and materials, relevant to Nepalese cultures and experiences, would need to be written and included in the curriculum (Eagle, 1999, p.318). Though ELT material production has already started, in the lack of corpus, it has not been materialized to the required extent.

- Corpus building has many implications including pedagogical ones. According to Aston (2001 b, p 3ff), corpora can provide teachers and learners with information about the language and the culture which can complement and integrate that available from other sources such as textbooks, teachers, and reference materials. (Cited in Seidlhofer, 2011).

- Corpus can be used to better prepare students to meet the demands of spoken English. Teachers can use corpus evidence to develop materials for students that more accurately reflect the spoken language.

- Corpus serves language teachers well by providing a basis for deciding which language features and structures are important and also how various features and structures are used (Reppen and Simpson, 2002, p.92.).

\section{Conclusion}

It is unlikely that the role of English in Nepalese education can be reduced in near future. Besides, penetration of English in Nepalese social life has consequently led to the growth of new English in Nepal with its own characteristic features.
However, in the lack of corpus, the legitimacy of Nepalese English is often questioned and the variety is perceived with disdain. Building of corpus for Nepalese English will pave the way for its authentication thereby developing dictionary and grammar. In this paper, I primarily propose that a comprehensive corpus is built for it to be standardized and its functions to be elaborated. Threats to local languages and cultures can be minimized once we own English and promote it incorporating Nepalese cultures and values.

\section{The Author}

Sajan Kumar Karn is a Lecturer in English Education at Tribhuvan University, Nepal. He has widely published on education, English Language Teaching and applied linguistics. So far he has published about two dozen articles in journals, has co-authored two titles on applied linguistics and has contributed in editing three prescribed texts on English literature for B. Ed. and M. Ed. namely, New Paradigms (2010) and Explorations in English (2011), and Reading beyond the Borders (2011). He has edited five volumes of 'ELT Today', Journal of NELTA Birguni and has been contributing as a co-editor of NELTA Choutari, a web-magazine. He is also a co-editor of Journal of NELTA and Academic Voices, a multidisciplinary journal. He has presented and participated in several national and international conferences home and abroad. He is more interested in the studies related to critical pedagogy and world Englishes.

\section{References}

Awasthi, J. R., Bhattarai, G. R. \& Khaniya, T. R. (eds.) (2008). New generation English. Kathmandu: Bidhyarthi Publication.

Bhattarai, G.R. \& Gautam, G. R. (2005). English Language Teachers at Crossroads. Journal of NELTA, 10, 1-5.

Bhattarai, G.R. \& Gautam, G. R. (2007). The proposed ELT survey: redefining the status and role of English in Nepal. Journal of NELTA, 12.1-2:32-35.

Brett, L. (1999). Standard English? Welcome to Nepal. Journal of NELTA, 4, 85-92.

Canagarajah, S. (1999). Resisting linguistic imperialism in English teaching. Oxford: Oxford University Press.

Cook, G. (2003). Applied linguistics. New York: Oxford University Press.

CDC (1999). Secondary curriculum introductory training booklet English. Bhaktpur: CDC.

Duwadi, E. P. (2010). Nenglish: An Inevitable Reality of Merely a Mirage. Journal of NELTA. 15, 43-53.

Daniloff-Merril, M.E. (2010). Nenglish and Nepalese 
Student Identity. Reinventing Identities in Second Language Writing. 240-256.

Eagle, S. (1999). The language situation in Nepal. Journal of Multilingual and Multicultural Development, 20. 4, 272-327.

Farrel Thomas S. C. \& Martin, S. (2009). To Teach Standard English or World Englishes? A Balanced Approach to Instruction. English Teaching Forum, 47. 2, 2-7.

Ferguson, G.(2006). Language planning and education. Edinburgh: Edinburgh University Press.

Giri, R. A. (2009). The Politics of 'Unplanning' of Languages in Nepal. Journal of NELTA, 14, 32-44.

Government of Nepal. (1990). Interim Constitution of Nepal. Kathmandu: Government of Nepal.

Graddol, D. (2006). English next. London: British Council.

Hartford, B. S. (2006). The Relationship of New Englishes and Linguistic Theory: A Cognitive Based Grammar of Nepali English. In Robert J. Baumgardner (Ed.) (2006), South Asian English (pp. 88-103). Delhi: Oxford University Press.

Harmer, J. (2007). The practice of English language teaching. London: Pearson Longman.

Kansakar, T. R. (1998). Higher Secondary and Three Year Bachelor English Curricula: A Case for Coordination. Journal of NELTA. 3.1-2.

Kansakar, T. R.(2011). The theory, practice and pedagogy of English as a foreign language in Nepal. In L. Farrel., U. N. Singh \& R. A. Giri (Eds.) (2011). English language education in south Asia (pp.123-135). New Delhi: Foundation Books.

Karn, S. K (2006). English: then, now and in the days ahead. Journal of NELTA, 11, 73-79.

Karn, S. K. (2009). Englishization is a bonus. Contemporary Issues in ELT, 58-62.

Karn, S. K. (2008, May 31). ELT Survey: Need of the Country. The Rising Nepal, p. 4.

Kumaravadivelu, B. (2001). Toward a post-method pedagogy. TESOL Quarterly, 35/4, 537-560.

Larsen-Freeman, D. (2007). Teaching and learning English: From ideology to empowerment. Journal of NELTA, 12, 67-74.
Low, M. \& Graham, B. (2000). English for beginners. Chennai: Orient Longman.

Malla, K. P. (1977). English in Nepalese education. Kathmandu: Ratna Pustak Bhandar.

NELTA (2010). Report of 15th international conference of Nepal English Language Teachers' Association. Retrieved on $4^{\text {th }}$ October, 2011 from www.nelta. org.np/15/15confreport.pdf.

Pennycook, A. (1994). The cultural politics of English as an international language. London: Longman.

Philipson, R. (2007). Linguistic imperialism. New Delhi: Oxford University Press.

Phyak, P. (2009). English language teaching policy in Nepal: promises and challenges of teachers. Contemporary Issues in ELT, 58-62.

Phyak, P. \& Karn, S. K. (2010). Identity and Variety in Learners' English: Building Corpus for Nepalese English. A paper presented at Asian English Spoken Language Corpus workshop on $23 \mathrm{rd}$ November, 2010 in Kathmandu.

Rai, V. S. (2006). English, Hinglish and Nenglish. Journal of NELTA, 11, 34-39.

Reppen, R. \& Simpson, R. (2003). Corpus linguistics. In Schmitt, N. (2003). An introduction to applied linguistics. UK: Hodder Education.

Seidlhofer, B. (2011). Controversies in applied linguistics. New York: Oxford University Press.

Sharma, B. K. (2008). World Englishes, English as a Lingua Franca, and English Pedagogy. Journal of NELTA, 13, 121-130.

Sharma, G. (2009). The English language in Nepal: Promises and Challenges for Teachers. Contemporary Issues in ELT. 15-19.

Sharma, K.C. (2006). English in Nepal from the past to present. Journal of NELTA, 11, 24-33.

Verma, Y. P. (2006). Some Features of Nepali Newspaper in English. In Robert J. Baumgardner (Ed.) (2006). South Asian English (pp.82-87). Delhi: Oxford University Press.

Yadav, Y. P. (2009). Linguistic Diversity in Nepal: Perspectives on MLE. A paper presented at $14^{\text {th }}$ International Conference of NELTA on February, 23rd, 2009 in Kathmandu. 


\begin{tabular}{|c|c|}
\hline \multicolumn{2}{|r|}{ Appendix I } \\
\hline Nepali English(Nep E) & Standard English(Std E) \\
\hline Wel come & Welcome \\
\hline Simple/simple-minded(adj.) & a. plain/unassuming \\
\hline & b.foolish/not intelligent \\
\hline proudy(adj.) & proud/not helpful \\
\hline romantic(adj.) & nice/pleasant \\
\hline bored(adj..) & $\begin{array}{l}\text { not interested/frustrated } \\
\text { annoyed/irritated }\end{array}$ \\
\hline ladies’ & women's/female \\
\hline peoples(n-pl) & people \\
\hline childrens (n-pl) & children \\
\hline persons(n-pl) & people (except in formal notices) \\
\hline officer(civilian) (n) & manager, supervisor, executive \\
\hline to be stationed $(\mathrm{v})$ & to be based \\
\hline officer's quarters(n) & $\begin{array}{l}\text { accommodation/on site } \\
\text { accommodation }\end{array}$ \\
\hline ten $\operatorname{class}(\mathrm{n})$ & class ten \\
\hline boarding school(no hostel) & Britain: Private day school \\
\hline Kindergarten & $\begin{array}{l}\text { First year of formal education (In European countries a } \\
\text { kindergarten is for non-formal learning) }\end{array}$ \\
\hline alphabets(n) & abc /letters \\
\hline Meena Miss(n) & $\begin{array}{l}\text { Miss Sharma/teachers are always addressed by their } \\
\text { surname preceded by Mr/Miss/Mrs }\end{array}$ \\
\hline tiffin carrer(n) & lunch box \\
\hline $\operatorname{dot} \operatorname{pen}(n)$ & biro/ ball point pen \\
\hline scale & ruler \\
\hline Ram sir & Mr. Ram \\
\hline Head Sir & $\begin{array}{l}\text { Principal, Head master/head mistress-referred to as Sir or } \\
\text { Madam or Miss }\end{array}$ \\
\hline Stitch machine(n) & stapler \\
\hline Ruling paper & lined paper \\
\hline Campus(n) & $\begin{array}{l}\text { secondary school (upto the equivalent of class 12) } \\
\text { university/college (if studying for a formal degree/ } \\
\text { diploma) }\end{array}$ \\
\hline My son reads in K.G. & $\begin{array}{l}\text { My son is in Kindergarten (as children neither read nor } \\
\text { study in kindergarten) }\end{array}$ \\
\hline He is fully confident of repeat exam. & He is fully confident of pasing the chance exam. \\
\hline The staffs are very political. & The staff are very political. \\
\hline Welcome speech & Welcoming address/speech \\
\hline Auspicious occasion & great occasion \\
\hline My best heroine & My favorite actress \\
\hline Cold store & Corner shop \\
\hline & Source: Brett, 1999, p. 92 \\
\hline
\end{tabular}




\section{Appendix II}

\section{Nenglish}

Dadu

Mamu

He is coming on Monday, is n't it?

You are coming with us, No?

Cheater

Sent up exam

Sharamless

Dimagless aaimaai

Rishi ji

Load Shedding

\section{English}

Dad

Mom

He is coming on Monday, is n't he?

You are coming with us, Are n't you?

Cheat

Send up exam

Shameless

Insane woman

Mr. Rishi

Power cut

\section{Some Nepali words that have entered English}

Yar, bazaar, fariya, himals, bar-peepal, bahun, khukuri, raksi, kurta salwar, gaine, bhauju, dai , didi, kaka, bhini, buhari, baje, hajor babu, kanchha, ammai, aaa

\section{Appendix IV}

Discuss about

Give answer

Saw dream

Open the radio

One of the pen

\section{Nepalese English Discourses}

S1: What class your brother reads in?

S2: He reads in K.G. in a BOARDING school.

S1: OPEN the fan, please.

S2: Sorry, there is no line.

$\mathrm{T}$ : Ramesh is a very TALENT student.

T: You are right but Dhanesh is more talent than Ramesh.

T: Do you speak English?

S: Why not?

- I would like to good morning you all present in this NELTA gathering. ( A teacher while addressing the mass in NELTA Makwanpur conference)

- Thousands of people scarified for loktantra_(democracy) in janaanodal-II(Revolution-II).

- The program was organised in Khulamuncha(Open theatre).

\section{Nepali Stylistic convention}

- $\quad$ Come sir.

- Check my copy sir.

- Write in your copy.

- I have a dot pen 


\section{English taught as Maths}

- $\quad$ Sub. + V1/V5 + object (Simple Present Tense)

- V1, V2, V3, V4, V5(Five forms of verb)

- Narration : Formula of SON (This refers to the fact that while changing pronouns in direct speech into indirect one, first person is changed according to subject, second person according to object and third person is not changed)

(Phyak \& Karn, 2010)

\section{Appendix IV \\ Nepalese English in Literature}

There, I sold gudpak, sweetmeats at Bus Park in the evening. .(Socrates' Footsteps by Govinda Raj Bhattarai, translated by Balram Adhikari(2010)

My Kaka, my Ama, my Buwa....(Fifteen and Three Quarters by Richa Bhattarai, 2011)

Achheta, Bindi, Chautari, Dhiki, Gundruk, Tamasuk, Khurpa, Jaulo, Sindoor, Lungi...(Rebel, Translated and Edited by Ramchandra K.. C., 2011) 